\title{
Muş Devlet Hastanesi Servis Etkinliklerinin Veri Zarflama Analizi ile Değerlendirilmesi ${ }^{1,2}$ (Araştırma Makalesi)
}

Evaluation of Mus State Hospital's Service Efficiencies with Data Envelopment Analysis

Doi: 10.29023/alanyaakademik.872062

\section{Özgür YEŞiLYURT}

Dr. Öğretim Üyesi, Muş Alparslan Üniversitesi, Să̆llk Bilimleri Fakültesi, Sosyal Hizmet Bölümü, o.yesilyurt@alparslan.edu.tr

Orcid No: 0000-0001-9252-3375

\section{Fuad SELAMZADE}

Dr. Öğretim Üyesi, Muş Alparslan Üniversitesi, Să̆lık Bilimleri Fakültesi, Sağlık Yönetimi Bölümü,.f.salamov@alparslan.edu.tr

Orcid No: 0000-0002-2436-8948

Bu makaleye atıfta bulunmak için: Yeşilyurt, Ö. \& Selamzade, F. (2021). "Muş Devlet Hastanesi Servis Etkinliklerinin Veri Zarflama Analizi ile Değerlendirilmesi”. Alanya Akademik Bakış, 5(2), Sayfa No.999-1014.

\begin{tabular}{|c|c|}
\hline & ÖZET \\
\hline Anahtar kelimeler: & $\begin{array}{l}\text { Çalışmanın amacı; Muş Devlet Hastanesindeki } 23 \text { servisin } 2014-2019 \text { yılları } \\
\text { için etkinliklerinin analiz edilmesidir. Çalışma parametrik olmayan Veri }\end{array}$ \\
\hline Muş Devlet & Zarflama Analizi (VZA) kullanılarak yapılmıştır. Sonrasında ilgili yıllar için \\
\hline Hastanesi, & üçer yılı kapsayan dört pencereden oluşan pencere analizleri ile servislerin \\
\hline Veri Zarflama & etkinlikleri ölçülmüş, servislerin ylllara göre etkinlik değişimleri ve \\
\hline Analizi, & Malmquist İndeksi Toplam Faktör Verimlilikleri hesaplanmıştır. CCR ve \\
\hline Hastane Etkinlik & $\begin{array}{l}\text { BCC hesaplamalarina göre sirasiyla } 2014 \text { 'te } 8 \text { ve } 12 ; 2015 \text { 'te } 8 \text { ve } 13 \text {; } \\
2016 \text { 'da } 7 \text { ve } 13 ; 2017^{\prime} \text { de } 8 \text { ve } 14 ; 2018 \text { 'de } 7 \text { ve } 12 ; 2019 \text { 'da } 4 \text { ve } 14 \text { servis }\end{array}$ \\
\hline $\begin{array}{l}\text { Makale Geliş Tarihi: } \\
\text { 18.02.2021 }\end{array}$ & $\begin{array}{l}\text { etkin çıkmıştır. Muş Devlet Hastanesi'nin servislerin birçoğunun son üç } \\
\text { vilda diğer villara göre daha etkin olduğu sonucuna varılmıstır. Buna ek }\end{array}$ \\
\hline $\begin{array}{l}\text { Kabul Tarihi: } \\
\text { 05.05.2021 }\end{array}$ & $\begin{array}{l}\text { olarak; etkin olmayan servislerin ise etkin olması için personel sayısı ve } \\
\text { yatak kapasitelerinin dağllımları ile ilgili düzenlemeye ihtiyaç } \\
\text { duyulmaktadır. }\end{array}$ \\
\hline
\end{tabular}

ABSTRACT

The purpose of study is to analyse the efficiencies of 23 services in Muş State hospital for 2014-2019 years. In the study, the analysis of non-parametric Data Envelopment Analysis (DEA) was performed. Then, the efficiency of the services was measured with window analyses consisting of four windows

\footnotetext{
${ }^{1} \mathrm{Bu}$ çalışma, Muş Alparslan Üniversitesi Bilimsel Araştırma ve Yayın Etiği Kurulu'nun 28.02.2019 tarih ve 01/11 sayılı kararınca "Etik Kurul Onayı" alınarak ve katılımcılara araştırma hakkında gerekli bilgilendirmeler yapılarak tamamlanmıştır.

${ }^{2}$ Bu çalışma, 22-23 Ekim tarihlerinde II. Uluslararası Muş Sempozyum'unda "Muş Devlet Hastanesi Servislerinde Etkinlik Analizi” isminde sözlü bildiri olarak sunulmuş olan çalışmanın geliştirilmiş ve revize edilmiş halidir.
} 
Keywords:

Muş State Hospital,

Data Envelopment

Analysis,

Hospital Efficiency covering three years each for the relevant years. After that, efficiency changes of the services by years and Malmquist Index Total Factor Productivities were calculated. According to the CCR and BCC method of DEA calculations respectively, 8 and 12 services in 2014; 8 and 13 services in 2015; 7 and 13 services in 2016; 8 and 14 services in 2017; 7 and 12 services in 2018; 4 and 14 services in 2019 were efficient. It was concluded that most of the services of Muş State Hospital were more efficient in the last three years compared to the other years. In addition to this, there is a need for regulation regarding the number of staff and the distribution of bed capacities to make inefficient services efficient.

\section{GİRİş}

Hastaneler, birden çok hizmetten oluşan karmaşık yapılardır. Hastanelerin temel amacı; zamanında, eşitlikçi, hasta merkezli, güvenli, verimli ve etkili ikinci basamak sağlık hizmetleri sunmaktır. Hastane tarafından sağlanan hizmetlerin kalitesi ne kadar yüksekse, etkinliği, hastaların memnuniyeti ve sağlık durumu dahil olmak üzere nihai sonuçları da o kadar iyi olacaktır. Bu nedenle, sunulan sağlık hizmetlerinin kalitesi etkinlik ile ilgilidir. Bununla birlikte, performans sadece bir kalite meselesi değil, aynı zamanda kaynak tüketimi ve sağlanan hizmetlerin verimliliğinin miktarının da bir fonksiyonudur (Chen vd., 2010: 341). Yani, hastaneler (diğer sağlık hizmet sunucuları gibi) genellikle hizmetlerinin kalitesini en üst düzeye çıkarma sorunuyla mücadele etmekte, aynı zamanda maliyetleri kontrol altına almaya çalışmakta ve bekleme sürelerini azaltmak için sunulan hizmetlerin çeşitliliğini ve sayısını artırmaktadırlar. Hastaneler hizmet üretirken kaliteden ödün vermeden performanslarını ve verimliliklerini artırmayı hedeflemektedirler. Diğer bir ifadeyle; hizmet üreten işletmelerin performans analizinde kaliteyi göz ardı etmemeleri gerekmektedir. Çünkü görünüşte verimli olan işletmelerin maliyet tasarrufları, kaliteden ve/veya etkinlikten ödün verdiklerinde ortaya çıkabilmektedir. Kaynak kullanımının verimliliğini hesaba katmayan işletmeler performans analizlerini yaparken sağlık sisteminin mali sürdürülebilirliğini tehlikeye atabilmektedirler.

Sağlık hizmeti sunumunda bazı bölgelerde zorluklar bulunmaktadır. Özellikle Doğu Anadolu Bölge'sinde personel sayısı ve yatak doluluk oranları ile ilgili bazı dönemlerde hasta sayılarındaki mevsimsel dalgalanmalardan da kaynaklı olarak sorunlar ortaya çıkabilmektedir. Bu sorunların ortadan kaldırılması yönünde sağlık yöneticileri tarafından çözüm önerilerinin geliştirilmesi ve özellikle kurumda etkin çalışmayan birimlerin belirlenerek gerekli önlemlerin alınabilmesinde bu çalışmanın yardımcı olması beklenmektedir. Ayrıca Doğu Anadolu'daki hastaneler için böyle bir çalışmanın literatürde yer almıyor alması bu çalışmamanın özgün değerini artırmaktadır.

Bu çalışmanın sağlık hizmetleri üretiminde kullanılan girdilerle en fazla çıktının elde edilmesi konusunda hastane yönetimine özellikle etkin çalışmayan birimlerle ilgili fikir vermesi hedeflenmektedir. Etkin çalışmayan birimlerin girdi miktarını düşürmek ve çıktı miktarını artırmak suretiyle etkin ve verimli çalışan birimler içerisinde yer almaları mümkün olacaktır. Etkin çalışmayan birimlerin karşılaşacağı sorunlardan biri de aksaklığa uğramayan sağlık hizmeti sunumu konusudur. Etkin çalışmayan birimlerin hastane kaynaklarını etkin kullanmamasından dolayı finansal sıkıntıya girmesi kaçınılmaz olacaktır. Hastanelerde verimlilik konusunu ön plana çıkaran durumlardan biri de hizmet üretiminde kullanılan kıt 
kaynakların üretim süreçlerinde etkin bir şekilde kullanmalarının sağlanmasıdır. Bu durum hastane performansını ve karlılığını artırmaktadır.

Çalışmada kullanılmış olan analizler Veri Zarflama Analizi, Pencere Analizi ve Malmquist İndeksi Toplam Faktör Verimlilik (TFV) analizidir. Çalışmanın amacı Muş Devlet Hastanesi'nde 23 servisin etkinliğinin 2014-2019 yıllarına ait veriler kullanılarak hesaplanmasıdır. Çalışmada kullanılan girdiler; doktor ve hastane yatak sayısı, çıktılar ise; polikliniklerde yapılan muayene sayısı, servislerde yatan sayısı ve hastanenin yıllık yatak doluluk oranıdır.

\section{LITERATÜR TARAMASI}

Sağlık alanında verimlik ve etkinlik konularını içeren birçok çalışma bulunmaktadır. Bu çalışmaları birden çok hastanenin etkinlik durumlarını ortaya koyan çalışmalar ve bir hastane üzerinden yapılan hastanedeki birimlerin etkinlik durumlarını ortaya koyan çalışmalar olmak üzere iki ayrı çerçevede değerlendirmek gerekmektedir.

Birden fazla hastane üzerinden yapılan ve birden çok hastanenin etkinlik durumunu ortaya koyan çalışmalardan bazıları aşağıdaki gibidir:

Ayanoğlu, Atan ve Beylik'in (2010) 2007 yılı verilerini kullanarak Sağlık Bakanlığı'na bağlı 16 hastane için 5 finansal girdi (ilk madde ve malzeme giderleri, personel ücret ve giderleri, dışarıdan sağlanan fayda ve hizmetler, diğer çeşitli giderler, amortisman ve tükenme payları) ve 1 finansal çıktı (hizmet gelirleri) kullanarak hastanelerin etkinlik ve karlılık durumlarını değerlendirmişlerdir. Yapılan analizler sonucunda hastanelerde \%13.43 oranında atıl harcama yapıldığı sonucuna varılmıştır.

Gülsevin ve Türkan'ın (2012), 2011 yılı verilerini kullanarak, Afyonkarahisar'daki hastanelerin etkinlik durumunu analiz etmiştir. Çalışmada 3 girdi (uzman hekim sayısı, hemşire sayısı ve toplam yatak sayısı) 4 çıktı (toplam ayaktan muayene sayısı, toplam yatan hasta sayısı, toplam taburcu olan hasta sayısı ve toplam ameliyat sayısı) değişkeni kullanılmıştır. Çalışmada 8 hastane \%100 etkin çıkmıştır.

Kawaguchi, Tone ve Tsutsui 'nin (2014), 2007-2009 dönemi için, Japonya'daki belediye hastanelerinin etkinliğini analiz ettiği oldukları çalışmada 2 farklı model kullanılmıştır. 1. modelde idari personel sayısı, bakım görevlisi sayıs1, yıllık faiz maliyeti, belediye sübvansiyonu ve tıbbi giderler girdi olarak kullanılmıştır. Çıktı olarak ise; sağlık gelirleri kullanılmıştır. 2. modelde doktor sayısı, hemşire sayısı, yardımcı hemşire sayısı, tıbbı teknoloji uzmanı sayısı girdi olarak kullanılmıştır. Çıktı olarak ise; ameliyat günü başına yatak hasta sayısı ve ameliyat günü başına ayaktan hasta sayısı ve acil servi yatak sayısı çıktı olarak kullanılmıştır. Çalışmada Japonya'daki reform politikalarının etkinlik üzerinde olumlu bir etkisinin olmadığı sonucuna varılmıştır.

Çalışkan ve Girginer'in (2016) Türkiye'deki hastanelerin performans durumlarını ortaya koymak için yapmış oldukları çalışma 4 girdi (uzman hekim sayısı, hemşire sayısı, diğer sağlık personeli sayısı ve yatak sayısı) ve 3 çıktı (ameliyat sayısı, yatak doluluk oranı ve yatan hasta sayısı) kullanılarak yapılmıştır. 81 ildeki hastaneler ait 2014 yılı verileri kullanılarak yapılan çalışmada 11 ildeki hastaneler etkin çıkmıştır.

Karadayı, Ekinci, Akkan ve Ülengin'in (2017) İstanbul ilindeki 7 hastanenin acil servis birim etkinliklerinin ölçmek için yapmış oldukları çalışmada 3 girdi (hekim sayısı, hemşire sayısı 
ve yatak sayısı) 2 çıktı (ortalama kaynak kullanım yüzdesi ve ortalama hasta bekleme süresi) kullanılmıştır. Çalışma sonucunda etkinlik skorları göz önünde bulundurulduğunda acil servis birimlerinin etkin olmadığı sonucuna varılmıştır.

Bir hastane üzerinden yapılan ve hastanedeki birimlerin etkinlik durumunu ortaya koyan çalışmalardan bazıları aşağıdaki gibidir:

Al-Shayea'nın (2011) Suudi Arabistan'da bulunan King Khalid Üniversitesi Hastanesi klinikleri için yaptıkları çalışmada etkinlik hesaplamasında 2 girdi (doktorların toplam maaşları ve hemşirelerin toplam maaşları) ve 3 çıtı (hizmet verilen hasta sayısı, yatak verimliliği ve ortalama devir aralığı) değişkeni kullanmışlardır. 9 departmandan 2'si 12 aylık periyotların tamamında \%100 etkin çıkmıştır.

Yiğit (2016) bir üniversite hastanesinin tıbbi birimlerinin verimlilik durumlarını ölçmek için yapmış olduğu çalışmada 4 girdi (hekim sayısı, asistan sayısı, yatak sayısı, personel ve nöbet giderleri uzman hekim sayısı, pratisyen hekim sayısı ve yatak sayısı) ve 5 çıktı (poliklinik sayısı, yatan hasta sayısı, yatak doluluk oranı (\%) ve sağlık hizmeti geliri) değişkeni kullanmıştır. Çalışma sonucunda hastane tıbbi birimlerinin \%45'inin verimli çalıştığı sonucuna varılmıştır. Buna ek olarak tıbbi birimlerin verimlilik ortalamaları \% 86.2 (CCR) ve \%93.4 (BCC) olarak bulunmuştur.

\section{YÖNTEM ve ARAŞTIRMA MODELI}

$\mathrm{Bu}$ çalışmada yer alan değişkenler, literatürde hastanelerin verimlilik ve etkinliklerini analiz eden çalışmalar kullanılarak oluşturulmuştur. Bu kapsamda bu çalışmada kullanılan girdi değişkenleri doktor ve hastane yatak sayısı; çıtı değişkenleri ise polikliniklerde yapılan muayene sayısı, servislerde yatan sayısı ve hastanenin yıllık yatak doluluk oranı olarak belirlenmiştir.

Çalışmada Veri Zarflama Analizi, Pencere Analizi ve Malmquist İndeksi Toplam Faktör Verimlilik (TFV) analizleri kullanılmıştır. Çalışmada kullanılan analizlerle ilgili genel bilgiler aşağıda verilmiştir.

Etkinliğin ölçülmesi konusunda literatürde yer alan öncü isimler olan Debreu (1951), Koopmans (1951) ve Farrell (1957) teknik etkinliği; üretilmesi gereken tüm çıktıların ortaya konulması varsayımına dayanarak üretim sürecinde kullanılan tüm girdilerin maksimum düzeyde azaltılması olarak tanımlamışlardır. Öncü olan çalışmalar genel çerçevede mal ve hizmet üretimi ve maliyet minimizasyonu fonksiyonlarını dikkate alarak işlem yapmaktadırlar. Etkinlik konusunda ilk ampirik çalışmalar Debreu ve Koopmans tarafından ortaya konulmuştur (Murillo-Zamorano ve Vega-Cervera, 2000).

$\mathrm{Bu}$ çalışmada etkinlik analizleri için Veri Zarflama Analizinin ölçeğe göre sabit getirili Charnes-Cooper-Rhodes (CCR) ve ölçeğe göre değişken getirili Banker-Charnes-Rhodes (BCC) yöntemleri kullanılmıştır. Ayrıca, yıl ve karar verici birim bazında servislerin etkinliklerin ölçülmesi için Pencere Analizi yapılmıştır. Bu analizlere ek olarak yıllara göre etkinlik değerlerinde meydana gelen değişmeler, Malmquist İndeksi Toplam Faktör Verimlilik Analizi kullanılarak test edilmiştir.

Charnes, Cooper ve Rhodes (1978)'in ortaya koymuş olduğu Veri Zarflama Analizi (VZA) etkinlik hesaplamaları için temel olarak kabul edilmektedir. Bu yaklaşımda birimin üretmiş olduğu y çıktısının (u ağırlığı ile), üretim süreçleri içerisinde kullanılan x girdisine (v ağırlığı 1002 
ile) bölünmesi ile denklem (1) yazılmaktadır (Charnes, Cooper ve Rhodes, 1978; Cooper, Seiford ve Zhu, 2011).

$$
\theta=\frac{\sum_{r=1}^{s} u_{r} y_{r o}}{\sum_{i=1}^{m} v_{i} x_{i o}}
$$

Girdi yönelimli bir doğrusal programlama denklemi oluşması için etkinlik analizlerinin hesaplanmasında, kesirli fonksiyonda yer alan amaç fonksiyonunun paydası 1'e eşitlenir. Çıktı yönelimli bir doğrusal programlama denklemi oluşması için etkinlik analizlerinin hesaplanmasında amaç fonksiyonunun payı 1'e eşitlenir. Bu eşitliğin anlamı girdilerin ağırlık toplamının 1 ile sınırlandırılmasıdır. Buna ek olarak ağırlıklar için uygun değerler seçilerek birimlerin ağırlıklı çıktı toplamının maksimize edilmesini ve etkinlik değerinin 1'i aşmamasını sağlamaktadır (2) (3) (Charnes, Cooper ve Rhodes, 1978: 431).

$$
\begin{gathered}
\operatorname{Max} \theta=\sum_{r=1}^{s} u_{r} y_{r o} ; \quad \sum_{i=1}^{m} v_{i} x_{i o}=1 \\
\text { Kisitlar: } \quad \frac{\sum_{r=1}^{s} u_{r} y_{r j}}{\sum_{i=1}^{m} v_{i} x_{i j}} \leq 1(j=1,2, \ldots n) ; \sum_{i=1}^{m} v_{i} x_{i j}=1 ; u_{r}>0 ; v_{i}>0 \\
\operatorname{Min} \theta=\sum_{i=1}^{m} v_{i} x_{i o} ; \quad \sum_{r=1}^{s} u_{r} y_{r o}=1 \\
\text { Kisitlar: } \frac{\sum_{r=1}^{s} u_{r} y_{r j}}{\sum_{i=1}^{m} v_{i} x_{i j}} \leq 1(j=1,2, \ldots n) ; u_{r}>0 ; v_{i}>0
\end{gathered}
$$

Literatürde sabit ölçek getirili CCR modeli olarak adlandırılan bu modele Banker, Charnes ve Cooper'ın bir kısıt $\left(e \lambda=\sum_{j=1}^{n} \lambda_{j}=1\right)$ eklemesiyle değişken ölçekli BCC modeli ortaya çıkmıştır. Bu kısıt $\lambda \mathrm{j} \geq 0 \mathrm{n}$ adet Karar Verici Birimin (KVB) farklı kombinasyonlarda iç bükey bir üst sınır çizgisi kapsamında oluşmasını sağlamaktadır (Banker, Charnes ve Cooper, 1984: 1086).

CCR ve BCC yöntemleri ile yapılan analizlerde KVB`lerin almış oldukları skorlarda 1 değeri tam etkinlik skorunu ifade etmektedir. KVB'nin CCR etkinlik skorunun BCC etkinlik skoruna bölünmesi ile ölçek etkinlik skoru bulunmaktadır (Kutlar ve Babacan, 2008: 154). 7

Veri Zarflama Analizi'nde karar verici birim sayılarının girdi ve çıktı değişken sayıları ile sınırlı olması durumunda zaman serbestliğinin düşük olması nedeniyle panel veri alınarak, parametrik olmayan yaklaşımlardan biri olan pencere analizi yapılmaktadır (Kutlar, Kabasakal ve Babacan, 2015: 78). T dönemi içerisinde s kadar çıktının üretilebilmesi için N adet karar verici birim için NxT gözlem ortaya çıkmaktadır. $t$ döneminde $n$ adet karar verici birimin $\mathrm{r}$ boyutlu girdi vektörü $\mathrm{x}_{\mathrm{t}}{ }^{\mathrm{n}}=\left(\mathrm{x}_{1 \mathrm{t}}{ }^{\mathrm{n}}, \mathrm{x}_{2 \mathrm{t}}{ }^{\mathrm{n}}, \ldots \mathrm{x}_{\mathrm{rt}}{ }^{\mathrm{n}}\right), \mathrm{s}$ boyutlu çıktı vektörü ise $\mathrm{y}_{\mathrm{t}}{ }^{\mathrm{n}}=\left(\mathrm{y}_{1 \mathrm{t}}{ }^{\mathrm{n}}, \mathrm{y}_{2 \mathrm{t}}{ }^{\mathrm{n}}, \ldots \mathrm{y}_{\mathrm{st}}{ }^{\mathrm{n}}\right)$ şeklinde ifade edilmektedir. Girdi yönelimli olarak ifade edilen pencere analizinin formülü (4) ölçeğe göre sabit getiri varsayımı gözönünde bulundurlarak aşağıdaki gibi yazllabilmektedir (Asmild, Paradi, Aggarwall ve Schaffnit, 2004: 70):

$$
\begin{gathered}
\theta_{\mathrm{kwt}}=\min _{\theta, \lambda} \theta \\
\text { Kisitlar: }-\mathrm{X}_{\mathrm{kw}} \lambda+\theta \mathrm{x}_{\mathrm{t}}{ }^{\prime} \geq 0 ; \mathrm{Y}_{\mathrm{kw}} \lambda-\mathrm{y}_{\mathrm{t}}{ }^{\prime} \geq 0 ; \lambda_{\mathrm{n}} \geq 0(\mathrm{n}=1,2, \ldots \mathrm{N})
\end{gathered}
$$

Caves, Christiensen ve Diewert (1982) tarafından geliştirilen Malmquist Toplam Faktör Verimlik İndeksi (TFV) (1953); üretimdeki değişmeyi baz almaktadır. Üretimdeki değişme, çok girdili ve çok çıktılı teknolojilerin temsil edildiği fark fonksiyonları ile modele dahil edilmiştir. Fiyatların belirlenmediği veya ilgili kurumdan alınamadığg durumlarda özellikle kamu kurum ve kuruluşlarında etkinliğin ölçülmesinde kullanılan bir yöntem olarak 
karşımıza çıkmaktadır. Ayrıca bu yöntem; üretim etkinliğini ve teknik etkinliği ayrı ayrı hesaplama imkânı vermektedir (Estache, De la Fe ve Trujillo, 2004). Buna ek olarak bu yöntemin hesaplanmasında Veri Zarflama Analizi kullanılarak teknik değişimin ve teknik etkinlikte orya çıkan değişimin ifade edildiği iki fonksiyon ortaya çıkmaktadır (Liu ve Wang, 2008).

Çıktı yönelimli Malmquist TFV değişim indeksinin s (baz dönemi) ve $t$ dönemleri için aşağıdaki gibi (5) yazılması mümkün olacaktır. Buna ek olarak; s dönemi referans olarak ele alındığında hesaplama aşağıdaki gibi (6) farklılık gösterecektir (Coelli, Rao, O'Donnell ve Battese, 1998: 291):

$$
\begin{aligned}
& m_{0}^{t}\left(y_{s}, x_{s}, y_{t}, x_{t}\right)=\frac{d_{0}^{t}\left(y_{t}, x_{t}\right)}{d_{0}^{t}\left(y_{s}, x_{s}\right)} \\
& m_{0}^{s}\left(y_{s}, x_{s}, y_{t}, x_{t}\right)=\frac{d_{0}^{s}\left(y_{t}, x_{t}\right)}{d_{0}^{s}\left(y_{s}, x_{s}\right)}
\end{aligned}
$$

(5) ve (6) numaralı denklemlerde görüldüğü gibi $\mathrm{d}_{0} \mathrm{~s}^{\mathrm{s}}\left(\mathrm{y}_{\mathrm{t}}, \mathrm{x}_{\mathrm{t}}\right)$ notasyonu $\mathrm{t}$ döneminden $\mathrm{s}$ dönemine kadar olan üretime konu olan unsurları göstermektedir.

Etkinlikteki değişimin anlamı; $\mathrm{t}$ dönemi içerisinde teknik etkinlik durumunun, s dönemindeki teknik etkinliğe oranıdır (7) (Candemir ve Deliktaş, 2006: 4).

$$
\text { Etkinlikteki Değișme (ED) }=\frac{d_{0}^{t}\left(y_{t}, x_{t}\right)}{d_{0}^{s}\left(y_{s}, x_{s}\right)}
$$

(7) numaralı denklemde etkinlik durumundaki değişim sabit getiri durumunda teknik etkinlikteki değişim indeksini ifade etmektedir. Bu indeks de s ve t dönemleri içerisinde en iyi üretim sınırını yakalamak anlamına gelmektedir. Teknolojik değişme indeksi teknik etkinlik sınırında meydana gelen değişimi ifade etmektedir (8).

$$
\text { Teknolojik Değișme (TED) }=\left[\frac{d_{0}^{s}\left(y_{t}, x_{t}\right)}{d_{0}^{t}\left(y_{t}, x_{t}\right)} x \frac{d_{0}^{s}\left(y_{s}, x_{s}\right)}{d_{0}^{t}\left(y_{s}, x_{s}\right)}\right]^{1 / 2}
$$

TFV'deki değişim teknik etkinlikteki değişme işle teknolojik değişmenin çarpılması ile bulunmaktadır (9).

$$
M_{T F V}^{s, t}=E D \times T E D
$$

TFV'deki değişim indeksinin 1'in üzerinde olması; TFV'nin s döneminden t dönemine kadar arttığını göstermektedir. TFV'deki değişim indeksinin 1'in altında olması ise TFV'nin azaldığını göstermektedir.

\section{VERILLRİN TOPLANMASI ve ANALİZi}

Çalışmada Muş Devlet Hastanesi'nden elde edilmiş veriler kullanılmıştır. Çalışmanın evrenini 2014-2019 yılları oluşturmaktadır. Muş Devlet Hastanesi'nin 23 servisinin etkinlik analizinin yapılması için girdi olarak; doktor ve hastane yatak sayısı, çıktı olarak; polikliniklerde yapılan muayene sayısı, servislerde yatan sayısı ve hastanenin yıllık yatak doluluk oranı kullanılmıştır. Çalışmada etik kurul kararı gerektiren klinik ve deneysel insan ve hayvanlar üzerindeki çalışmalar yapılmamış ve bu nedenle etik kurul kararı gerekmemektedir. Tablo 1’de çalışmada kullanılan girdi ve çıktı değişkenlerine ait istatistikler sunulmuştur. 
Tablo 1. Girdi ve Çıktı Değişkenlerine ait Tanımlayıcı İstatistikler

\begin{tabular}{|c|c|c|c|c|c|}
\hline \multirow{2}{*}{ Gösterge } & \multicolumn{2}{|c|}{ Girdiler } & \multicolumn{3}{|c|}{ Çıktılar } \\
\hline & Doktor & Yatak & Muayene & Yatan & Doluluk \\
\hline \multicolumn{6}{|c|}{2014} \\
\hline Max & 7 & 60 & 75816 & 7761 & 87.49 \\
\hline Min & 1 & 1 & 333 & 38 & 25.53 \\
\hline Ort. & 2.70 & 18.39 & 25310.20 & 1172.30 & 51.04 \\
\hline Std. S & 1.52 & 16.14 & 21306.20 & 1658.90 & 14.73 \\
\hline \multicolumn{6}{|c|}{2015} \\
\hline Max & 5 & 56 & 73295 & 8205 & 149.57 \\
\hline Min & 1 & 2 & 406 & 33 & 26.73 \\
\hline Ort. & 2.97 & 15.87 & 26392.20 & 1165 & 77.20 \\
\hline Std. S & 1.40 & 14.60 & 20719.80 & 1747.90 & 34.90 \\
\hline \multicolumn{6}{|c|}{2016} \\
\hline Max & 8 & 64 & 83913 & 8862 & 112.69 \\
\hline Min & 1 & 2 & 240 & 26 & 22.46 \\
\hline Ort. & 3.26 & 17.04 & 27009 & 1124.30 & 61.85 \\
\hline Std. S & 2.11 & 17.52 & 23352.90 & 1923.50 & 23.62 \\
\hline \multicolumn{6}{|c|}{2017} \\
\hline Max & 8 & 64 & 96374 & 9267 & 124.85 \\
\hline Min & 1 & 2 & 324 & 25 & 13.24 \\
\hline Ort. & 3.61 & 16.22 & 31057.40 & 1176.10 & 57.80 \\
\hline Std. S & 2.34 & 16.61 & 25912.80 & 1953.50 & 24.80 \\
\hline \multicolumn{6}{|c|}{2018} \\
\hline Max & 8 & 64 & 94997 & 8749 & 188.52 \\
\hline Min & 1 & 2 & 1039 & 33 & 18.26 \\
\hline Ort. & 3.17 & 16.22 & 32168.80 & 1233.20 & 70.50 \\
\hline Std. S & 1.71 & 16.61 & 25499.70 & 1868.20 & 40.10 \\
\hline \multicolumn{6}{|c|}{2019} \\
\hline Max & 9 & 64 & 68729 & 9282 & 161.45 \\
\hline Min & 1 & 3 & 862 & 20 & 12.42 \\
\hline Ort. & 3.26 & 15.83 & 28173.30 & 1330.80 & 71.20 \\
\hline Std. S & 1.98 & 16.22 & 21076.20 & 1961.40 & 38.80 \\
\hline
\end{tabular}

Muş Devlet Hastanesi'nden elde edilmiş istatistiklerine göre, 2014-2019 yılarında en fazla Doktor ve Yatak sayısına sahip olan birim Çocuk Sağlığı ve Hastalıkları servisi olnuştur. 2014-2019 yillarında en az Doktor sayısına sahip olan birim Endokrinoloji ve Metabolizma Hastalıkları ve Nefroloji servisleri, Yatak sayısında ise Deri ve Zührevi Hastalıkları ve Göğüs Cerrahisi servisleri olmuştur.

İstatistiklere göre çıktı değişkenleri 2014, 2017-2019 yıllarında en fazla Poliklinik muayene sayısı gerçekleşmiş birim Çocuk Sağlığı ve Hastalıkları servisi, 2015 ve 2016 yıllarında ise İç Hastalıkları servisi olmuştur. 2014-2019 yılarında en fazla Yatan hasta sayısına sahip olan birim Kadın Hastalıkları ve Doğum servisi, Yatak Doluluk Oranı en fazla olan birimler 2014 ve 2016 yıllarında Kulak, Burun, Boğaz Hastalıkları, 2015 yılında Enfeksiyon Hastalıkları ve Klinik Mikrobiyoloji ve 2017-2019 yıllarında Plastik, Rekonstrüktif ve Estetik Cerrahi servisleri olmuştur. Poliklinik muayene sayısı en az olan birimler 2014-2018 yıllarında Göğüs Cerrahisi, 2019 yılında Nefroloji servisi olmuştur. 2014-2019 yıllarında en az Yatan Hasta 
sayısı Deri ve Zührevi Hastalıkları servisinde, en az Yatak Doluluk oranı Deri ve Zührevi Hastalıkları servislerinde olmuştur.

\section{BULGULAR}

Çalışmada Muş Devlet Hastanesi'nde yer alan yataklı servislerin etkinlik düzeyleri Veri Zarflama Analizi ile analiz edilmiştir. Çalışmada girdi yönelimli ölçeğe göre sabit getirili CCR ve ölçeğe göre değişken getirili BCC yöntemleri kullanılmıştır. Tablo 2'de analiz sonuçları yer almaktadır.

Tablo 2`de verilen ölçeğe göre sabit getirili CCR yöntemi ile yapılmış etkinlik analizi sonuçlarına göre 2014, 2015 ve 2017 yıllarında 8, 2016 ve 2018 yılında 7, 2019 yılında ise 4 servisin etkin olduğu görülmektedir. Deri ve Zührevi Hastalıkları birimi tüm yıllarda, Plastik, Rekonstrüktif ve Estetik Cerrahi 2014 ve 2016-2019, Kadın Hastalıkları ve Doğum 20142018, Göğüs Cerrahisi 2014, 2017-2019, Kulak Burun Boğaz Hastalıkları 2015, 2016 ve 2018, Göz Hastalıkları 2014, 2017 ve 2018, Endokrinoloji ve Metabolizma Hastalıkları 20152017 yıllarında etkin olmuşlardır. Tam etkinliğe en yakın skoru alan servisler; 2014, yılında Nefroloji (0.928), 2015 yılında İç Hastalıkları (0.827), 2016 ve 2018 yıllarında Çocuk Cerrahisi (0.955; 0.913), 2017 ve 2019 yıllarında Kulak Burun Boğaz Hastalıkları (0.988 ve $0.980)$ olmuştur.

Servislerin etkinlik analizleri sonucunda göre 2014 yılında Kalp ve Damar Cerrahisi (0.398), 2015 yılında Göğ̈̈s Hastalıkları (0.303), 2016 yılında Ruh Sağlığı ve Hastalıkları (0.340), 2017 ve 2018 yıllarında Enfeksiyon Hastalıkları ve Klinik Mikrobiyoloji (0.380 ve 0.355) ve 2019 yılında Endokrinoloji ve Metabolizma hastalıkları (0.139) en düşük etkinlik skoru almış servisler olmuşlardır. 2014-2019 dönemi için CCR yöntemi kullanılarak elde edilen etkinlik skorları incelendiğinde ortalama etkinlik skorlarının 0.703-0.787 aralığında değiştiği görülmektedir. Bununla birlikte tam etkinliğe sahip servis sayısı yıldan yıla azalmaktadır. 2014 yılında tam etkinliğe sahip olan birim sayısı 8 iken, 2019 yılında 4 olmuştur.

Tablo 2`de verilen ölçeğe göre değişken getirili BCC analiz sonuçları incelendiğinde 2014 ve 2018 yıllarında 12, 2015 ve 2016 yılında 13, 2017 ve 2019 yillarında 14, 2019 yılında 9 servisin etkin olduğu görülmektedir. Çocuk sağlığı ve hastalıkları, Deri ve Zührevi Hastalıklar, Endokrinoloji ve Metabolizma, Gögüs Cerrahisi, Göz Hastalıkları, İç Hastalıkları, Kadın Hastalıkları ve Doğum, Kulak Burun Boğaz Hastalıkları, Nefroloji ve Plastik, Rekonstrüktif ve Estetik Cerrahisi birimleri tüm yıllarda, Çocuk Cerrahisi 2014 ve 2016-2018, Enfeksiyon Hastalıkları 2015, Fiziksel T1p ve Rehabilitasyon 2015-2017, Gastroenteroloji 2015-2019, Gögüs Hastalıkları 2014 ve 2017, Kalp Damar Cerrahisi 2019, Kardiyoloji 2015, Nöroloji 2019 ve Üroloji birimleri 2019 yıllarında etkin olmuşlardır. BCC yöntemi ile yapılmış analizlerde en düşük etkinlik skorunu almış birimler; 2014 yılında Kalp ve Damar Cerrahisi (0.424), 2015 yılında Göğüs Hastalıkları (0.391), 2016 yılında Ruh Sağlığı ve Hastalıkları (0.375), 2017 yılında Ortopedi ve Travmatoloji (503), 2018 ve 2019 yıllarında Genel Cerrahi (0.591 ve 0.482) birimleri olmuştur. BCC yöntemi ile elde edilmiş ortalama etkinlik skorları 2014-2019 yılarında 0.813-0.869 aralığında değişmektedir.

Tablo 2. Servislerin CCR ve BCC Yöntemleri ile Elde Edilmiș Etkinlik Skorları

\begin{tabular}{|c|c|c|c|c|c|c|c|c|c|}
\hline \multirow[b]{2}{*}{ Birim } & \multicolumn{3}{|l|}{2014} & \multicolumn{3}{|l|}{2015} & \multicolumn{3}{|l|}{2016} \\
\hline & $\begin{array}{l}\text { CCR } \\
\text { Skoru }\end{array}$ & $\begin{array}{l}\text { BCC } \\
\text { Skoru }\end{array}$ & Ölçek & $\begin{array}{l}\text { CCR } \\
\text { Skoru }\end{array}$ & $\begin{array}{l}\text { BCC } \\
\text { Skoru }\end{array}$ & Ölçek & $\begin{array}{l}\text { CCR } \\
\text { Skoru }\end{array}$ & $\begin{array}{l}\text { BCC } \\
\text { Skoru }\end{array}$ & Ölçek \\
\hline
\end{tabular}




\begin{tabular}{|c|c|c|c|c|c|c|c|c|c|}
\hline Beyin ve Sinir Cer. & .62 & .83 & I & .54 & .57 & I & .71 & .76 & $\mathrm{I}$ \\
\hline Çocuk Cer. & 1.00 & 1.00 & $\mathrm{C}$ & .62 & .72 & $\mathrm{C}$ & .96 & 1.00 & $\mathrm{D}$ \\
\hline Çocuk Sağ. ve Hast. & .92 & 1.00 & $\mathrm{D}$ & .78 & 1.00 & $\mathrm{D}$ & .83 & 1.00 & $\mathrm{D}$ \\
\hline Deri ve Zührevi Hast. & 1.00 & 1.00 & $\mathrm{C}$ & 1.00 & 1.00 & $\mathrm{C}$ & 1.00 & 1.00 & $\mathrm{C}$ \\
\hline Endokrinoloji ve Metab. & .85 & 1.00 & I & 1.00 & 1.00 & $\mathrm{C}$ & 1.00 & 1.00 & $\mathrm{C}$ \\
\hline Enfeksiyon hast. & .40 & .53 & I & 1.00 & 1.00 & $\mathrm{C}$ & .49 & .52 & I \\
\hline Fiziksel Tıp ve Rehab. & .69 & .71 & $\mathrm{D}$ & 1.00 & 1.00 & $\mathrm{C}$ & 1.00 & 1.00 & $\mathrm{C}$ \\
\hline Gastroenteroloji & .61 & .64 & I & 1.00 & 1.00 & $\mathrm{C}$ & 1.00 & 1.00 & $\mathrm{C}$ \\
\hline Genel Cer. & .67 & .68 & $\mathrm{D}$ & .43 & .43 & I & .89 & .96 & $\mathrm{D}$ \\
\hline Göğüs Cer. & 1.00 & 1.00 & $\mathrm{C}$ & .30 & 1.00 & $\mathrm{C}$ & .45 & 1.00 & I \\
\hline Göğüs Hast. & 1.00 & 1.00 & $\mathrm{C}$ & .30 & .39 & $\mathrm{C}$ & .64 & .71 & I \\
\hline Göz Hast. & 1.00 & 1.00 & $\mathrm{C}$ & .62 & 1.00 & $\mathrm{D}$ & .89 & 1.00 & $\mathrm{D}$ \\
\hline İç Hast. & 1.00 & 1.00 & $\mathrm{C}$ & .83 & 1.00 & $\mathrm{D}$ & .59 & 1.00 & $\mathrm{D}$ \\
\hline Kadın Hast. ve Doğum & 1.00 & 1.00 & $\mathrm{C}$ & 1.00 & 1.00 & $\mathrm{C}$ & 1.00 & 1.00 & $\mathrm{C}$ \\
\hline Kalp ve Damar Cer. & .40 & .42 & I & .59 & .63 & $\mathrm{C}$ & .37 & .43 & I \\
\hline Kardiyoloji & .73 & .76 & $\mathrm{D}$ & 1.00 & 1.00 & $\mathrm{C}$ & .48 & .48 & I \\
\hline Kulak Burun Boğaz Hast. & .77 & 1.00 & $\mathrm{D}$ & 1.00 & 1.00 & $\mathrm{C}$ & 1.00 & 1.00 & $\mathrm{C}$ \\
\hline Nefroloji & .93 & 1.00 & I & .50 & 1.00 & $\mathrm{C}$ & .70 & 1.00 & I \\
\hline Nöroloji & .85 & .99 & $\mathrm{D}$ & .58 & .59 & I & .67 & .73 & $\mathrm{D}$ \\
\hline Ortopedi ve Travm. & .51 & .52 & $\mathrm{D}$ & .59 & .60 & $\mathrm{D}$ & .56 & .57 & $\mathrm{D}$ \\
\hline Plastik Cer. & 1.00 & 1.00 & $\mathrm{C}$ & .51 & .69 & $\mathrm{C}$ & 1.00 & 1.00 & $\mathrm{C}$ \\
\hline Ruh Sağ. ve hast. & .53 & .71 & I & .33 & .42 & I & .34 & .38 & I \\
\hline Üroloji & .57 & .58 & $\mathrm{I}$ & .66 & .66 & $\mathrm{D}$ & .56 & .61 & I \\
\hline Ortalama & .79 & .84 & & .70 & .81 & & .74 & .84 & \\
\hline \multirow[b]{2}{*}{ Birim } & \multicolumn{3}{|l|}{2017} & \multicolumn{3}{|l|}{2018} & \multicolumn{3}{|l|}{2019} \\
\hline & $\begin{array}{l}\text { CCR } \\
\text { Skoru } \\
\end{array}$ & $\begin{array}{l}\text { BCC } \\
\text { Skoru }\end{array}$ & Ölçek & $\begin{array}{l}\text { CCR } \\
\text { Skoru } \\
\end{array}$ & $\begin{array}{l}\text { BCC } \\
\text { Skoru }\end{array}$ & Ölçek & $\begin{array}{l}\text { CCR } \\
\text { Skoru } \\
\end{array}$ & $\begin{array}{l}\text { BCC } \\
\text { Skoru }\end{array}$ & Ölçek \\
\hline Beyin ve Sinir Cer. & .75 & .76 & I & .59 & .66 & I & .59 & .62 & I \\
\hline Çocuk Cer. & 1.00 & 1.00 & $\mathrm{C}$ & .91 & 1.00 & I & .53 & .59 & I \\
\hline Çocuk Sağ. ve Hast. & .92 & 1.00 & $\mathrm{D}$ & .76 & 1.00 & $\mathrm{D}$ & .84 & 1.00 & $\mathrm{D}$ \\
\hline Deri ve Zührevi Hast. & 1.00 & 1.00 & $\mathrm{C}$ & 1.00 & 1.00 & $\mathrm{C}$ & 1.00 & 1.00 & $\mathrm{C}$ \\
\hline Endokrinoloji ve Metab. & 1.00 & 1.00 & $\mathrm{C}$ & .66 & 1.00 & I & .14 & 1.00 & $\mathrm{D}$ \\
\hline Enfeksiyon hast. & .38 & .57 & I & .36 & .71 & I & .56 & .81 & I \\
\hline Fiziksel Tıp ve Rehab. & .82 & 1.00 & $\mathrm{D}$ & .87 & .87 & I & .85 & .88 & $\mathrm{D}$ \\
\hline Gastroenteroloji & .85 & 1.00 & I & .77 & 1.00 & I & .83 & 1.00 & I \\
\hline Genel Cer. & .57 & .58 & $\mathrm{C}$ & .55 & .59 & I & .48 & .48 & $\mathrm{D}$ \\
\hline Göğüs Cer. & 1.00 & 1.00 & $\mathrm{C}$ & 1.00 & 1.00 & $\mathrm{C}$ & 1.00 & 1.00 & $\mathrm{C}$ \\
\hline Göğüs Hast. & 1.00 & 1.00 & $\mathrm{C}$ & .57 & .60 & I & .70 & .71 & $\mathrm{D}$ \\
\hline Göz Hast. & 1.00 & 1.00 & $\mathrm{C}$ & 1.00 & 1.00 & $\mathrm{C}$ & .93 & 1.00 & $\mathrm{D}$ \\
\hline
\end{tabular}




\begin{tabular}{llllllllll} 
İç Hast. & .65 & 1.00 & $\mathrm{D}$ & 1.00 & 1.00 & $\mathrm{C}$ & .55 & 1.00 & $\mathrm{D}$ \\
Kadın Hast. ve Doğum & 1.00 & 1.00 & $\mathrm{C}$ & 1.00 & 1.00 & $\mathrm{C}$ & .87 & 1.00 & $\mathrm{D}$ \\
Kalp ve Damar Cer. & .47 & .61 & $\mathrm{C}$ & .69 & .87 & $\mathrm{I}$ & .80 & 1.00 & $\mathrm{I}$ \\
Kardiyoloji & .49 & .52 & $\mathrm{I}$ & .58 & .62 & $\mathrm{I}$ & .49 & .50 & $\mathrm{D}$ \\
Kulak Burun Boğaz Hast. & .99 & 1.00 & $\mathrm{D}$ & 1.00 & 1.00 & $\mathrm{C}$ & .98 & 1.00 & $\mathrm{D}$ \\
Nefroloji & .66 & 1.00 & $\mathrm{I}$ & .51 & 1.00 & $\mathrm{I}$ & .54 & 1.00 & $\mathrm{I}$ \\
Nöroloji & .81 & .81 & $\mathrm{I}$ & .57 & .64 & $\mathrm{I}$ & 1.00 & 1.00 & $\mathrm{C}$ \\
Ortopedi ve Travm. & .50 & .50 & $\mathrm{C}$ & .70 & .73 & $\mathrm{I}$ & .76 & .78 & $\mathrm{D}$ \\
Plastik Cer. & 1.00 & 1.00 & $\mathrm{C}$ & 1.00 & 1.00 & $\mathrm{C}$ & 1.00 & 1.00 & $\mathrm{C}$ \\
Ruh Sağ. ve hast. & .58 & .68 & $\mathrm{C}$ & .51 & .67 & $\mathrm{I}$ & .49 & .61 & $\mathrm{I}$ \\
Üroloji & .67 & .67 & $\mathrm{D}$ & .84 & .85 & $\mathrm{I}$ & .86 & 1.00 & $\mathrm{D}$ \\
\hline Ortalama & .79 & .86 & & .76 & .86 & & .73 & .87 & \\
\hline I- Artan, C- Sabit, D - Azalan & & & & & & & & \\
\hline
\end{tabular}

Tablo 3'te Muş Devlet Hastanesi servisleri için hesaplanmış Pencere Analizi sonuçlarına yer verilmiştir. Literatürde yer alan çalışmalarda pencere analizleri yaygın olarak üçer yıllık dönemler dikkate alınarak yapılmaktadır. Bu bağlamda bu çalışmada da pencere analizleri üçer yılık dönemler itibariyle yapılmıştır. CCR yöntemi ile yapılmış Pencere Analizi incelendiğinde yalnız 4. pencerede, yani 2017, 2018 ve 2019 yıllarında etkin olan tek servisin Deri ve Zührevi Hastalıkları birimi olduğu görülmektedir. Diğer birimler farklı yıllarda etkin olmuş olsalar bile, üç yıl art-arda etkin olmadığ 1 için pencere analizlerinde etkin olarak görülmemişlerdir. Şöyle ki, 1. ve 2. pencerelerde (2014-2015-2016 ve 2015-2016-2017) Deri ve Zührevi Hastalıkları (0.978 ve 0.926), 3. pencerede (2016, 2017, 2018) Kadın Hastalıkları ve Doğum (0.980) birimleri en yüksek etkinlik skorları almışlardır. 4. Pencerede Göz hastalıkları birimi 0.955 etkinlik skoru ile tam etkinliğe en yakın skoru almıştır. CCR yöntemi ile yapılmış Pencere Analizi sonuçlarına göre, 1. ve 2. Pencerelerde Ruh Sağlığı ve Hastalıkları (0.336 ve 0.315) 3. ve 4. Pencerelerde ise Enfeksiyon Hastalıkları ve Klinik Mikrobiyoloji (0.288 ve 0.361$)$ birimleri en düşük etkinlik skoru almış birimler olmuştur. CCR yöntemi ile yapılmış Pencere Analizi sonucunda pencerelerin etkinlik skoru ortalaması 0.625-0.663 arasında gerçekleşmiştir.

Tablo 3. Servislerin CCR ve BCC Yöntemleri ile Elde Edilmiş Pencere Analizi Etkinlik Skorları

\begin{tabular}{lllllllll}
\hline \multirow{3}{*}{ Birimler } & \multicolumn{1}{l}{ 1. Pencere } & \multicolumn{2}{l}{ 2. Pencere } & \multicolumn{2}{l}{ 3. Pencere } & \multicolumn{2}{c}{ 4. Pencere } \\
\cline { 2 - 9 } & $\mathbf{2 0 1 4 - 2 0 1 5 - 2 0 1 6}$ & $\mathbf{2 0 1 5 - 2 0 1 6 - 2 0 1 7}$ & $\mathbf{2 0 1 6 - 2 0 1 7 - 2 0 1 8}$ & $\mathbf{2 0 1 7 - 2 0 1 8 - 2 0 1 9}$ \\
\cline { 2 - 9 } & CCR & BCC & CCR & BCC & CCR & BCC & CCR & BCC \\
& Skoru & Skoru & Skoru & Skoru & Skoru & Skoru & Skoru & Skoru \\
\hline Beyin ve Sinir Cer. & .56 & .64 & .54 & .59 & .57 & .59 & .57 & .63 \\
Çocuk Cer. & .66 & .72 & .75 & .81 & .74 & .89 & .50 & .85 \\
Çocuk Sağ. ve Hast. & .72 & .93 & .69 & .98 & .75 & 1.00 & .68 & .91 \\
Deri ve Zührevi Hast. & .98 & .98 & .93 & 1.00 & .87 & .99 & 1.00 & 1.00 \\
Endokrinoloji ve Metab. & .78 & 1.00 & .90 & 1.00 & .86 & 1.00 & .53 & 1.00 \\
Enfeksiyon hast. & .52 & .67 & .52 & .67 & .29 & .50 & .36 & .61 \\
Fiziksel Tip ve Rehab. & .74 & .75 & .78 & .80 & .84 & .87 & .72 & .74 \\
Gastroenteroloji & .69 & .84 & .78 & 1.00 & .74 & 1.00 & .72 & 1.00
\end{tabular}




\begin{tabular}{lllllllll} 
Genel Cer. & .52 & .55 & .51 & .52 & .56 & .59 & .42 & .43 \\
Göğ̈üs Cer. & .41 & 1.00 & .42 & 1.00 & .68 & 1.00 & .89 & 1.00 \\
Göğüs Hast. & .56 & .62 & .48 & .62 & .70 & .72 & .64 & .70 \\
Göz Hast. & .79 & .80 & .72 & .86 & .83 & .94 & .96 & 1.00 \\
İç Hast. & .76 & .96 & .60 & 1.00 & .69 & .99 & .71 & .93 \\
Kadın Hast. ve Doğum & .83 & .91 & .85 & .99 & .98 & 1.00 & .76 & 1.00 \\
Kalp ve Damar Cer. & .35 & .42 & .37 & .50 & .37 & .52 & .60 & .78 \\
Kardiyoloji & .64 & .65 & .60 & .60 & .42 & .43 & .48 & .49 \\
K.B.B. Hast. & .81 & .89 & .83 & 1.00 & .73 & .99 & .89 & .96 \\
Nefroloji & .52 & 1.00 & .48 & 1.00 & .50 & 1.00 & .49 & 1.00 \\
Nöroloji & .64 & .65 & .56 & .57 & .55 & .55 & .68 & .73 \\
Ortopedi ve Travm. & .49 & .49 & .47 & .48 & .51 & .52 & .58 & .59 \\
Plastik Cer. & .73 & .88 & .77 & .88 & .84 & .95 & .92 & .94 \\
Ruh Sağ. ve hast. & .34 & .44 & .32 & .40 & .34 & .43 & .47 & .59 \\
Üroloji & .50 & .54 & .52 & .54 & .50 & .57 & .68 & .75 \\
\hline Ortalama & .63 & .75 & .63 & .77 & .65 & .78 & .66 & .81 \\
\hline
\end{tabular}

Tablo 3'te BCC yöntemi ile yapılmış Pencere Analizi sonucuna göre tüm pencerelerde yani tüm yıllarda etkin olan birimler; Endokrinoloji ve Metabolizma Hastalıkları, Gögüs Cerrahisi ve Nefroloji birimleri olmuştur. Ayrıca, Gastroenteroloji birimi 2., 3. ve 4., Deri ve Zührevi Hastalıkları 2. ve 4., Kadın Hastalıkları ve Doğum 3. ve 4., İç Hastalıkları ve Kulak Burun Boğaz Hastalıkları 2. ve Çocuk Sağlığı ve Hastalıkları 3. Pencerelerde tam etkinlik skoru almışlardır. Şöyle ki, 1. Pencerede 3., 2. Pencerede 7, 3. ve 4. Pencerelerde 6, birim etkin olmuştur. En düşük etkinlik skoru almış birimler; 1. pencerede Kalp ve Damar Cerrahisi (0.423), 2. ve 3. pencerelerde Ruh Sağlığ ve Hastalıkları (0.401 ve 0.425$)$ ve 4. pencerede Genel Cerrahi (0.429) birimleri olmuştur. BCC yöntemi ile yapılmış Pencere Analizi sonucunda pencerelerin etkinlik skoru ortalaması 0.753-0.810 arasında olmuştur.

Tablo 4 te servislerin yıllara göre Toplam Faktör Verimliliği (TFV) ortalama skorları sunulmuştur. Tüm Malmquist İndeksi ortalamalarının geometrik ortalamalar skorlarının 1 `in altında olması etkinliğin azalmasını, 1'e eşit olması etkinlikte değişimin olmamasını, skorların 1 'in üzerinde olması ise etkinliğin artmasını gösterir. Servislerin yılların ortalamasına göre elde edilen etkinlik değişiminin (effch) 2015-2016 (1.077) ve 2016-2017 (1.072) yıllarında arttığı, diğer yıllarda ise 1'in altında gerçekleştiği görülmüştür. Etkinlik değişiminin tüm yıllara göre ortalaması 0.979 olarak gerçekleşmiştir.

Servislerin yılların ortalamasına göre elde edilen teknik değişiminin (techch) 2014-2015 y1lında \%37.6, 2017-2018 y1lında \%21.0 ve 2018-2019 y1lında \%0.3 oranında arttığ 1 , 20152016 yılında \%22.5, 2016-2017 yılında \%9.8 oranında azaldığı tespit edilmiştir. Teknik değişim ortalaması 1.031 olarak gerçekleşmiştir. Servislerin etkinlik değişiminin yüksek olduğu yıllarda teknik değişiminin düşük, etkinlik değişiminin düşük olduğu yıllarda ise teknik değişiminin yüksek olduğu tespit edilmiştir.

Etkinlik değişimi ve teknik değişimin çarpımından elde edilen toplam TFV skorları (tfpch) 2014-2015 yılında \%19.3, 2017-2018 yıllarında \%16.8 oranında artmış, 2015-2016 yılında \%16.5, 2016-2017 yılında \%6.3 2018-2019 yıllarında ise \%7.5 oranında azalmıştır. 20142019 yılları TFV ortalamasının hemen hiç değişmediği (1.010) yaklaşık \%1 oranında arttığ1 görülmektedir. 
Muş Devlet Hastanesi servislerinin yılların ortalamasına göre elde edilmiş saf etkinlik değişimi (pech) yalnız 2014-2015 yıllarında \%4.9 oranında düşmüş, diğer yıllarda ise artarak, 1.026, 1.047, 1.014 ve 1.001 değerleri almıştır. Saf etkinlik değişimin en yüksek olduğu dönem \%4.7 lik değişim ile 2016-2017 yılları olmuştur.

Servislerin yıllara göre ölçek etkinlik değişim (sech) ortalaması incelendiğinde görülüyor ki, 2015-2016 ve 2016-2017 yıllarında artma, diğer yıllarda azalma olmuştur.

Tablo 4. Servislerin Malmquist İndeksi (Yılların Ortalamasına Göre)

\begin{tabular}{llllll}
\hline Servisler & effch & techch & pech & sech & tfpch \\
\hline $2014-2015$ & .87 & 1.38 & .95 & .91 & 1.19 \\
$2015-2016$ & 1.08 & .78 & 1.03 & 1.05 & .84 \\
$2016-2017$ & 1.07 & .90 & 1.05 & 1.02 & .97 \\
$2017-2018$ & .97 & 1.21 & 1.01 & .95 & 1.17 \\
$2018-2019$ & .93 & 1.00 & 1.00 & .93 & .94 \\
\hline Ortalama & .98 & 1.03 & 1.01 & .97 & 1.01 \\
\hline
\end{tabular}

Tablo 5 `e Muş Devlet Hastanesi servislerinin etkinlik değişimi ortalamaları, Malmquist İndeksi Toplam Faktör Verimliliği skorları verilmiştir. Tabloda sunulan veriler birimlerin 2014-2019 yıllarındaki değişimlerin geometrik ortalamasından elde edilmiştir.

Tablo 5`te görüldüğü üzere servislerin 2014-2019 yıllarının Toplam Faktör Verimliliği ortalamasına göre Kalp ve Damar Cerrahisi (\%24.5), Plastik Cerrahi (\%19.6), Üroloji (\%15.8), Gastroenteroloji (\%13.5), Enfeksiyon Hastalıkları (\%13.3), Göğüs Cerrahisi (\%12.6), Kadın Hastalıkları ve Doğum (\%8.3), Kulak Burun Boğaz Hastalıkları (\%7.1), Ortopedi ve Travmatoloji (\%5.9), Çocuk Cerrahisi, (\%5.6), Fiziksel Tıp ve Rehabilitasyon (\%2.2) ve Nefroloji (\%0.7) birimleri 1 `in üzerinde değer aldığı tespit edilmiştir. Nöroloji aldığı 0.999 TFV skoru ile 1`e en yakın skoru almıştır ve bu skorla Nöroloji biriminin TFV'de değişiklik olmadığı söylenebilmektedir.

Tablo 5. Servislerin Malmquist İndeksi (Birimlerin Ortalamasına Göre)

$\begin{array}{llllll}\text { Servisler } & \text { effch } & \text { techch } & \text { pech } & \text { sech } & \text { tfpch } \\ \text { Beyin ve Sinir Cer. } & .99 & .98 & .94 & 1.05 & .97 \\ \text { Çocuk Cer. } & .88 & 1.20 & .90 & .98 & 1.06 \\ \text { Çocuk Sağ. ve Hast. } & .98 & .99 & 1.00 & .98 & .97 \\ \text { Deri ve Zührevi Hast. } & 1.00 & .88 & 1.00 & 1.00 & .88 \\ \text { Endokrinoloji ve Metab. } & .70 & 1.09 & 1.00 & .70 & .76 \\ \text { Enfeksiyon hast. } & 1.07 & 1.06 & 1.09 & .98 & 1.13 \\ \text { Fiziksel Tıp ve Rehab. } & 1.04 & .98 & 1.04 & 1.00 & 1.02 \\ \text { Gastroenteroloji } & 1.06 & 1.07 & 1.09 & .97 & 1.14 \\ \text { Genel Cer. } & .93 & 1.04 & .93 & 1.00 & .97 \\ \text { Göğüs Cer. } & 1.00 & 1.13 & 1.00 & 1.00 & 1.13 \\ \text { Göğüs Hast. } & .93 & .98 & .93 & 1.00 & .91 \\ \text { Göz Hast. } & .99 & .95 & 1.00 & .99 & .93 \\ \text { İç Hast. } & .89 & .92 & 1.00 & .89 & .82\end{array}$




$\begin{array}{llllll}\text { Kadın Hast. ve Doğum } & .97 & 1.11 & 1.00 & .97 & 1.08 \\ \text { Kalp ve Damar Cer. } & 1.15 & 1.08 & 1.19 & .97 & 1.25 \\ \text { Kardiyoloji } & .92 & 1.03 & .92 & 1.01 & .95 \\ \text { Kulak Burun Boğaz Hast. } & 1.05 & 1.02 & 1.00 & 1.05 & 1.07 \\ \text { Nefroloji } & .90 & 1.12 & 1.00 & .90 & 1.01 \\ \text { Nöroloji } & 1.03 & .97 & 1.00 & 1.03 & 1.00 \\ \text { Ortopedi ve Travm. } & 1.08 & .98 & 1.08 & 1.00 & 1.06 \\ \text { Plastik Cer. } & 1.00 & 1.20 & 1.00 & 1.00 & 1.20 \\ \text { Ruh Sağ. ve hast. } & .98 & .95 & .97 & 1.02 & .94 \\ \text { Üroloji } & 1.08 & 1.07 & 1.12 & .97 & 1.16 \\ \text { Ortalama } & .98 & 1.03 & 1.01 & .97 & 1.01\end{array}$

Endokrinoloji ve Metabolizma Hastalıkları, Genel Cerrahi ve Kardiyoloji servislerinin teknik değişimi 1 'in üzerinde olmasına rağmen etkinlik değişim değerlerinin 1 'in altında gerçekleşmesi nedeni ile Toplam Faktör Verimliliği endeksleri 1 'in altında olduğu ortaya çıkmıştır. Beyin ve Sinir Cerrahisi, Çocuk Cerrahisi, Göğüs Hastalıkları, Göz Hastalıkları, İç Hastalıkları ve Ruh Sağlığı ve Hastalıkları servislerinin hem etkinlik değişimi hem de teknik değişiminde azalma olmuştur ve dolayısı ile TFV değerleri de 1 'in altında gerçekleşmiştir. Deri ve Zührevi hastalıkları biriminin etkinlik değişiminde değişme gerçekleşmemesine rağmen teknik değişimi 0.882 değeri aldığı için TFV değeri 0.832 olmuştur. Kalp ve Damar Cerrahisi 1.245 ile en fazla, Endokrinoloji ve Metabolizma Hastalıkları ise 0.760 ile en az TFV skoru almış servisler olmuşlardır.

\section{TARTIŞMA ve SONUÇ}

Muş Devlet Hastanesi'nin servislerinin 2014-2019 verileri ile etkinlik durumlarının analiz edilmesi ve etkin olmayan birimlerin belirlenmesi bu etkin olmama durumlarının ortadan kaldırılması konusunda sağlık yöneticilerine çözüm önerilerinin sunulması bu çalışma ile amaçlanmaktadır. Bu bağlamda etkinlik analizlerinin hesaplanması için parametrik olmayan veri zarflama analizinin girdi yönelimli ölçeğe göre sabit getirili CCR, ölçeğe göre değişken getirili BCC, Pencere analizleri ve Malmquist İndeksi Toplam Faktör Verimliliği analizleri kullanılmıştır.

Analiz sonuçlarına göre ölçeğe göre sabit getirili CCR yöntemi ile yapılmış analizlerde 2014, 2015 ve 2017 yıllarında 8, 2016 ve 2018 yılında 7, 2019 yılında ise 4 servis etkin olmuştur. Deri ve Zührevi Hastalıkları birimi tüm yıllarda, Plastik, Rekonstrüktif ve Estetik Cerrahi 2014 ve 2016-2019, Kadın Hastalıkları ve Doğum 2014-2018, Gögüs Cerrahisi 2014, 2017 2019, Kulak Burun Boğaz Hastalıkları 2015, 2016 ve 2018, Göz Hastalıkları 2014, 2017 ve 2018, Endokrinoloji ve Metabolizma Hastalıkları 2015-2017 yıllarında etkin olmuşlardır. Ölçeğe göre değişken getirili BCC yöntemi ile elde edilmiş etkinlik analizi sonuçlarına göre 2014 ve 2018 yıllarında 12, 2015 ve 2016 yılında 13, 2017 ve 2019 yıllarında 14, 2019 yılında 9 servisin etkin olduğu görülmektedir. Çocuk sağlığı ve hastalıkları, Deri ve Zührevi Hastalıklar, Endokrinoloji ve Metabolizma, Göğüs Cerrahisi, Göz Hastalıkları, İç Hastalıkları, Kadın Hastalıkları ve Doğum, Kulak Burun Boğaz Hastalıkları, Nefroloji ve Plastik, Rekonstrüktif ve Estetik Cerrahisi birimleri tüm yıllarda, Çocuk Cerrahisi 2014 ve 2016-2018, Enfeksiyon Hastalıkları 2015, Fiziksel Tip ve Rehabilitasyon 2015-2017, 
Gastroenteroloji 2015-2019, Göğüs Hastalıkları 2014 ve 2017, Kalp Damar Cerrahisi 2019, Kardiyoloji 2015, Nöroloji 2019 ve Üroloji birimleri 2019 yıllarında etkin olmuşlardır.

CCR yöntemi ile yapılmış Pencere Analizi incelendiğinde yalnız 4. pencerede, yani 2017, 2018 ve 2019 yıllarında etkin olan tek servisin Deri ve Zührevi Hastalıkları birimi olduğu görülmektedir. Diğer birimler farklı yıllarda etkin olmuş olsalar bile, üç yıl art-arda etkin olmadığı için pencere analizlerinde etkin olarak görülmemişlerdir. Şöyle ki, 1. ve 2. pencerelerde (2014-2015-2016 ve 2015-2016-2017) Deri ve Zührevi Hastalıkları, 3. pencerede $(2016,2017,2018)$ Kadın Hastalıkları ve Doğum birimleri en yüksek etkinlik skorları almışlardır. BCC yöntemi ile yapılmış Pencere Analizi sonucuna göre tüm pencerelerde yani tüm yıllarda etkin olan birimler; Endokrinoloji ve Metabolizma Hastalıkları, Gögüs Cerrahisi ve Nefroloji birimleri olmuştur. Ayrıca, Gastroenteroloji birimi 2., 3. ve 4., Deri ve Zührevi Hastalıkları 2. ve 4., Kadın Hastalıkları ve Doğum 3. ve 4., İç Hastalıkları ve Kulak Burun Boğaz Hastalıkları 2. ve Çocuk Sağlığı ve Hastalıkları 3. Pencerelerde tam etkinlik skoru almışlardır. Şöyle ki, 1. Pencerede 3., 2. Pencerede 7, 3. ve 4. Pencerelerde 6, birim etkin olmuştur.

Toplam Faktör Verimliliği ortalamalarına göre Kalp ve Damar Cerrahisi, Plastik Cerrahi, Üroloji, Gastroenteroloji, Enfeksiyon Hastalıkları, Göğüs Cerrahisi, Kadın Hastalıkları ve Doğum, Kulak Burun Boğaz Hastalıkları, Ortopedi ve Travmatoloji, Çocuk Cerrahisi, Fiziksel Tıp ve Rehabilitasyon ve Nefroloji birimleri 1'in üzerinde değer aldığı tespit edilmiştir. Nöroloji aldığı 0.999 TFV skoru ile 1’e en yakın skoru almıştır ve bu skorla Nöroloji biriminin TFV'de değişiklik olmadığı söylenebilmektedir.

$\mathrm{Bu}$ çalışma bir hastanedeki servislerin etkinliklerini ortaya koyduğu için literatürde yer alan birden fazla hastanenin karşılaştırmalı etkinliklerini içeren çalışmalarla karşılaştırılmamış olup bir hastanenin servislerinde etkinliğin ölçüldüğü çalışmalarla karşılaştırmalar yapılmıştır. Bu bağlamda yapılan karşılaştırmalar aşağıdaki gibidir:

Yiğit'in (2016) bir üniversite hastanesinin tıbbi birimlerinin etkinlik ve verimlilik durumlarını ölçmek için yapmış olduğu çalışmada hekim sayısı, asistan sayısı, yatak sayısı, personel ve nöbet giderleri, uzman hekim sayısı, pratisyen hekim sayısı ve yatak sayısı olmak üzere 4 girdi değişkeni kullanılarak analizler yapılmıştır. Buna ek olarak çalışmada poliklinik sayısı, yatan hasta sayısı, yatak doluluk oranı (\%) ve sağlık hizmeti geliri olmak üzere 5 çıtı değişkeni kullanılarak analizler yapılmıştır. Çalışmada CCR modeline göre 9 birim (B2, B4, B8, B10, B12, B14, B15, B18, B20) etkin çıkmıştır. Çalışmada BCC modeline göre 14 birim (B2, B4, B6, B7, B8, B9, B10, B11, B12, B14, B15, B16, B18, B20) etkin ç1kmıştır. Tarafımızdan yapılan çalışmayla kıyaslandığında CCR modeline göre etkin çıkan servis sayıları 2014, 2015 ve 2017 yıllarında 8, 2016 ve 2018 yılında 7, 2019 yılında ise 4 servisin etkin olduğu; BCC modeline göre etkin çıkan servis sayıları ise 2014 ve 2018 yıllarında 12, 2015 ve 2016 yılında 13, 2017 ve 2019 yıllarında 14, 2019 yılında 9 servis şeklinde çıkmıştır. Yiğit (2016) çalışmasında etkin çıkan ve çıkmayan birimler verilmediği için etkin çıkan veya çıkmayan birimlerle ilgili bilgi verilememiştir.

Al-Shayea'nın (2011) bir üniversite hastanesi klinik etkinliklerini ölçmek için yapmış oldukları çalışmada doktorların toplam maaşları ve hemşirelerin toplam maaşları olmak üzere 2 girdi değişkeni kullanılarak analizler yapılmıştır. Buna ek olarak hizmet verilen hasta sayısı, yatak verimliliği ve ortalama devir aralığı olmak üzere 3 çıktı değişkeni kullanılarak analizler yapılmıştır. Çalışmada 9 departmandan 2 si etkin çıkmıştır. Tarafımızdan yapılan çalışmada 
ise; 2019 y1lı için CCR yöntemiyle yapılan analizde 23 birimden 2'si; BCC yöntemi ile yapılan analizde 23 servisten 14'ü etkin çıkmıştır.

Etkinlik analizi sonucunda CCR ve BCC yöntemleri ile yapılan analizlerde tam etkin olan servisin ölçeğe göre sabit özellik gösterdiği görülmüştür. Yıllara göre ölçeğe göre artan ve ölçeğe göre azalan etki gösteren birimler yıllara göre eşit dağıldığı gözlemlenmiştir. Ölçeğe göre sabit getiriye sahip olan birimler literatürde verilen tanım gereği görece ölçek etkin olmuş birimlerdir. Ölçeğe göre azalan getiri özelliği gösteren birimlerinin bir takım dişsal faktörlerin etkisinden dolayı ölçeğe göre azalan getiri özelliği göstermişlerdir. Bu durumun çözülmesi için birimlerin kapasitelerini düşürmeleri ve kaynaklarını daha etkin kullanmaları, gerekirse girdileri azaltmaları gerekmektedir. Ölçeğe göre artan getiri özelliği gösteren birimler benzer girdiler ile daha fazla çıktı üretebilecekleri durumunda iken kapasitelerinin altında çıktı ürettikleri söylenebilmektedir. Ölçeğe göre artan özelliği gösteren birimler, kaynaklarını tam kapasitede kullanarak görece etkin hale gelebilecekleri söylenebilir.

\section{KAYNAKÇA}

AL-SHAYEA, M. A., (2011). "Measuring hospital's units efficiency: A data envelopment analysis approach". International Journal of Engineering \& Technology IJET - IJENS 11(06): 7-14.

ASMILD, M., PARADI, J. C., AGGARWALL, V. and SCHAFFNIT, C. (2004). "Combining DEA window analysis with the Malmquist index approach in a study of the Canadian banking industry". Journal of Productivity Analysis, 21: 67-89.

AYANOĞLU, Y., ATAN, M. ve BEYLİK, U. (2010). "Hastanelerde veri zarflama analizi (VZA) yöntemiyle finansal performans ölçümü ve değerlendirilmesi”. Sağlıkta Performans ve Kalite Dergisi, 2(2): 40-62.

BANKER, R. D., CHARNES, A. and COOPER, W.W. (1984). "Some models for estimating technical and scale inefficiencies in data envelopment analysis". Management Science, 30(9): 1078-1092.

CANDEMİR, M. ve DELIKKTAŞ, E. (2006). TİGEM işletmelerinde teknik etkinlik, ölçek etkinliği, teknik ilerleme, etkinlikteki değişme ve verimlilik analizi: 1999-2003, Ankara: TİGEM Yayın 141.

CAVES, D., CHRISTIENSEN, L. R. and DIEWERT, W. E., (1982), "The economic theory of indeks numbers and the mesurement of input, output and productivity". Econometrica, 50: 1393-1414.

CHARNES, A., COOPER, W.W. and RHODES, E. (1978). "Measuring the efficiency of decision making units". North-Holland Publishing Company European Journal of Operational Research. 2: 429-444.

CHEN, L, ASHIK, K, GUTERMAN, S, RIDGWAY, A, ORAV, E., and EPSTEIN A. (2010), Hospital cost of care, quality of care, and readmission rates: penny wise and pound foolish? JAMA Intern Med, 170(4),340-6. DOI:10.1001/archinternmed.2009.511

COELLI, T. J., RAO, D.S.P., O'DONNELL, C. J. and BATTESE, G. E. (1998). An introduction to efficiency and productivity analysis. Second Edition. New York: Springer. 
COOPER, W. W., SEIFORD, L. M.and ZHU, J. (2011). Handbook on data envelopment analysis. Second Edition, New York: Springer.

ÇALIŞKAN, S. ve GİRGINER, N. (2016). Türkiye'deki hastanelerin performanslarının veri zarflama analizi ile değerlendirilmesi. EconWorld2016@ImperialCollege Proceedings. London, 1-11.

DEBREU, G. (1951). “The coefficient of resource utilization”. Econometrica, 19(3): 273292.

ESTACHE, A., DE La FE, B. T. and TRUJILLO, L. (2004), "Sources of efficiency gains in port reform: a DEA decomposition of a Malmquist TFP indeks for Mexico", Utulities Policy, 12: 221-230.

FARREL, M. J. (1957). "The measurement of productive efficiency". Journal of the Royal Statistical Society. Series A (General), 120(3): 253-290.

GÜLSEVIN, G., ve TÜRKAN, A. H. (2012). "Afyonkarahisar hastanelerinin etkinliklerinin veri zarflama analizi ile değerlendirilmesi”. Afyon Kocatepe Üniversitesi Fen ve Mühendislik Bilimleri Dergisi, 12(2): 1-8.

KARADAYI, M. A., EKİNCİ, Y., AKKAN, C. ve ÜLENGİN, F. (2017). "İstanbul için acil servis birimlerinin etkinliğinin kategorik veri zarflama analizi ile değerlendirilmesi”. Journal of Yaşar University, 12: 31-39.

KAWAGUCHI, H., TONE, K. and TSUTSUI, M. (2014). "Estimation of the efficiency of Japanese hospitals using a dynamic and network data envelopment analysis model". Health Care Manag Sci, 17: 101-112.

KOOPMANS, T. C. (1951). Activity analysis of production and allocation. New York: John Wiley and Sons Inc.

KUTLAR, A., KABASAKAL, A. ve BABACAN, A. (2015). "Dynamic efficiency analysis of Turkish banks: a DEA-window and Malmquist index analysis for the 2003-2012 period". Sosyoekonomi, 24: 71-97.

LIU, F. F. and WANG, P. H. (2008). "DEA Malmquist productivity measure: Taiwanese semiconductor companies”. International Journal of Production Ecoonomic, 112: 367379.

MALMQUIST, S., (1953), "Indeks number and indifferences surfaces". Trabajos De Estatistica, 4: 209-242.

MURILLO-ZAMORANO, L. R. and VEGA-CERVERA, J. (2000). The use of parametric and non parametric frontier methods to measure the productive efficiency in the industrial sector. A comparative study. Department of Economics and Related Studies University of York. Discussion Papers in Economics. 17.

YİĞİT, V. (2016). "Bir üniversite hastanesinin tıbbı bölümlerinin teknik verimlilik analizi”. Süleyman Demirel Üniversitesi Sosyal Bilimler Enstitüsü Dergisi, (23): 199-214. 